\title{
Alcohol, betel-nut and cigarette consumption are negatively associated with health promoting behaviors in Taiwan: A cross-sectional study
}

\author{
Su-Er Guo ${ }^{1}$, Tung-Jung Huang ${ }^{2}$, Jui-Chu Huang ${ }^{3}$, Ming-Shyan Lin ${ }^{4}$, Rei-Mei Hong ${ }^{5}$, Chia-Hao Chang ${ }^{5}$
} and Mei-Yen Chen ${ }^{5^{*}}$

\begin{abstract}
Background: Oral cancer is the $2^{\text {nd }}$ most common cause of death due to cancer in the south-western coastal region of Taiwan; the standardized mortality of oral cancer is higher than elsewhere in the world. According to the evidence, alcohol, betel-nut and cigarette $(A B C)$ consumption cause oral, nasopharyngeal and related cancers. This study describes the relationships between $A B C$ consumers and health promoting behaviors among community adults living around an area with a high prevalence of oral cancer.

Methods: A population-based, cross-sectional study design was conducted in oral cancer epidemic areas in south-western coastal Taiwan in 2010, 6,203 community residents over 20 years of age participated.

Demographic data, $A B C$ habits, and health-promoting behaviors were explored. A logistic regression analyses were used to identify factors associated with $A B C$ consumers.

Results: A high percentage of participants consumed alcohol, betel-nut and cigarettes. Betel-nut and cigarette consumers took low levels of exercise, adopted a poor diet, and had poor oral hygiene. After adjusting for potential confounders, the logistic regression model indicated that middle aged males of poor education and low economic status, who did not exercise regularly and had poor oral hygiene, were more likely to chew betel quid and smoke cigarettes.

Conclusions: It has identified that BC consumers are negatively associated with health promoting behaviors. Further research is required to understand the reasons why the subjects consume $A B C$, and explore ways to prevent initiation and enhance cessation of $A B C$ habits in this population.
\end{abstract}

Keywords: Alcohol, Betel-nut, Cigarette, Nursing-led community health, Health promotion, Oral cancer

\section{Background}

Nurse-led health promotion program to prevent chronic disease and related cancers

Each year the International Council of Nurses (ICN) provides a theme or mission on International Nurse's Day for global nursing reflection and direction. During the last 5 years (2008-2012) themes have concerned serving communities, with nurses leading primary health care, chronic care and closing the gap from evidence to

\footnotetext{
* Correspondence: meiyen@gw.cgust.edu.tw

${ }^{5}$ College of Nursing \& the Chronic Diseases and Health Promotion Research Center, Chang Gung University of Science and Technology, No. 2, Chia-pu Rd. West Sec, Putz City, Chiayi County 61363, R.O.C. Taiwan

Full list of author information is available at the end of the article
}

action [1]. These missions motivated community nurses in Taiwan to actively participate in providing health promotion programs, cooperating with public health nurses, school health nurses and faculty members from the schools of nursing to take a leading role concerning community health development. The World Health Organization (WHO) has said that "chronic diseases, such as heart disease, stroke, cancer, chronic respiratory diseases and diabetes, correspond to $63 \%$ of all deaths in the world" [2]. Alcohol and cigarettes contribute to these chronic diseases [3], and $\mathrm{ABC}$ consumption causes oral cancer [4]. In this study, the authors found that "the incidence of oral cancer is 123-fold higher in $\mathrm{ABC}$ consumption, compared to non- $\mathrm{ABC}$ consumption" [4].

\section{Ciomed Central}


Twenty years ago, 10\% Taiwanese over 15 years old were $\mathrm{ABC}$ users [5]. In particular, betel nut trees became a significant agricultural product in Taiwan [6]. Therefore, reducing $\mathrm{ABC}$ consumption is increasingly important in promoting health.

According to ICD-10, oral cancer in the south-western coastal region of Yunlin County is ranked as the $2^{\text {nd }}$ most common cause of death from cancer in males, and its standardized mortality rate $(34 / 100,000)$ is higher than that of the Taiwanese nation $(14.9 / 100,000)$ and throughout the rest of the world [7]. Some of the mechanisms and specific risk factors associated with developing cancer remain unknown. However, the majority of factors associated with oral cavity-related cancers, including the oral sub-mucosa, tongue and nasopharynx, are related to alcohol, betel quid (areca nut) chewing and cigarette smoking [8-11]. Of these 3 habits, chewing betel quid, widespread in Southern Asian populations, is the major factor that causes oral cancer $[10,12]$. This habit is common in Taiwanese adolescents and adults with a poor educational level, and in minority populations in rural areas [12].

According to the mission of ICN, nurses are expected to serve communities and lead community health facilities. Therefore, this research team conducted a longitudinal study, based on community health assessment through a health promotion program, with the aim of reducing $\mathrm{ABC}$ consumption.

\section{Issues of $A B C$}

Over-consumption of alcohol harms health and social relationships, and, according to [13], excess alcohol consumption results in 2.5 million deaths every year. It can result in cardiovascular diseases, liver cirrhosis, hypertension, diabetes, dyslipidemia, abdominal obesity, metabolic syndrome, various cancers and several psychosocial related issues [14]. Numerous studies show that alcohol consumption is strongly associated with morbidity, mortality, and social problems in developing and developed countries $[1,14,15]$.

Chewing betel quid is significantly associated with adverse health effects, including oral and pharyngeal cancer, sub-mucosal fibrosis, gum disease, obesity, metabolic syndrome, hypertension and cardiovascular mortality $[8,12,13]$. Betel quid chewing is a common habit in Southern Asian populations, e.g. Malaysia, India, Pakistan, Sri Lanka, Myanmar, Thailand and Taiwan [8], and its contribution to the development of oral sub-mucosal fibrosis and oral cancer confirmed $[9,16]$. Retrospective studies indicated that many betel quid users combine this with alcohol consumption and cigarette smoking [7]. Cigarette smoking is responsible for several adverse cardiovascular and respiratory outcomes $[17,18]$. Combined with betel quid chewing it also has a significant contribution (86.5\%) to the risk of oral leukoplakia and oral sub-mucosal fibrosis [16].

Despite numerous studies reporting that the mechanism of $\mathrm{ABC}$ habits are associated with oral cancer, those that focus on combining $\mathrm{ABC}$ habits with adopting health promoting behavior in areas with a high prevalence of oral cancer are scarce. The purpose of this article, therefore, has been to outline the first phase of a longitudinal study and decide whether $A B C$ is associated with poor health promotion.

\section{Methods}

\section{Design, sample and setting}

This study is the first part of the longitudinal study of health promotion for community health development lead by nursing faculty members (HPCHN) around areas in south-western coastal Yunlin County, Taiwan, where oral cancer is endemic. Using a descriptive crosssectional design, this community-based survey was implemented every Monday to Saturday from October 2010 to September, 2011. Of 47,798 residents living in 27 villages, the response rate was $14.5 \%(6,911)$. The participants were selected by convenience sampling at the villages in the south-western coastal areas. The inclusion criteria were adults: (1) aged 20 years and over, (2) fully independent in managing their daily lives, (3) able to complete the questionnaires in Mandarin or Taiwanese dialects either by self-administration or at interview, without serious mental problems, (4) able to walk to a community center or the corporate private hospital, and (5) who agreed to sign an informed consent before being enrolled in the study. A total of 6,203 community residents participated.

\section{Procedure and ethical considerations}

This study was conducted with a corporate private hospital (135 beds) through the community health screening program, and approved by the institutional review board ethical committee (Chang-Gung Memorial Hospital Ethics Committee No 99-2501B). The interviewing procedures and privacy protection were explained to the participants by the research assistants. There were 2 stages in the set-up: (1) A systematic literature reviews needed to draw up the first version of the questionnaire. $\mathrm{ABC}$ were used as the major keywords to search PubMed, Ovid and the Chinese database from 1980 to 2011. (2) Face and content validity was judged to be good $(\mathrm{CVI}=0.90-0.92)$ by a panel of 5 experts - public health and health education faculty members, metabolic physicians, and nursing faculty members teaching health promotion. Some items within the instruments were revised according to the experts' suggestions.

All research assistants were trained for 4 hours by the investigators. Research assistants were senior nursing 
students in a Post-RN Bachelor of Nursing Degree Program who held registered nursing license and received 2 consequent training programs, each of 2 hours duration. In session 1, we focused on understanding research background and practicing interview skills. In session 2, 20 research assistants were grouped into 10 pairs to pretest and be familiar with all items of the questionnaire. Finally, research assistants were divided 2 groups to interview each elder and a $90 \%$ correct rate of inter-rater reliability was confirmed among the 10 pairs. The questionnaire consisted of 2 sections and the characteristics of the participant, as described below.

\section{Instruments}

$A B C$ habits were measured using 5 questions: (A) 'do you drink alcohol?' Participants were classified as 'less consumption' if they had never drank alcohol or had not drank for one year, or 'regular consumption' if they were currently drinking'; (B) 'do you chew betel-nut?' Participants were classified as 'less consumption' if they had never chewed betel-nut or no longer chewed', or 'regular consumption' if they were currently chewing one quid or more per day' [4]; (C) 'do you smoke cigarettes?' Participants were classified as 'less consumption' if they rarely or never smoked or 'regular consumption' if they were a current smoker one cigarette or more per day' [4]; (D) 'when did you begin to consume alcohol, betel nut chewing or smoke cigarettes?' if participants answered that they no longer partook of these 3 habits, they were asked question (E). 'How long is it since you quit drinking alcohol, betel nut chewing or smoking cigarettes?'

Health-promoting behavior was measured using 5 items including physical activity, requiring participants to answer the questions: (A) 'do you take regular exercise?' Participants were classified as 'not often' if their answer was never or sometimes, or 'often' if they usually exercised for $>30$ min per day, 3 times per week, or 150 minutes per week. (B) Vegetable and fruit habits: 'do you have 3 portions of vegetables and 2 portions of fruit every day? The answer was classified as 'not often' if they answered never or sometimes, and as 'often' if they usually had at least 3 portions or one and half bowl-sized portions of vegetables, and at least 2 portions or one bowl-size of fruit $>5$ days per week. (C) Regular dental check-up behavior: 'do you generally go to the dental clinic for a check up every half-year?' the answer was classified as 'not regular' if the answer was never or more than one year before visiting a dentist, or 'regular' if they answered that they attended regularly or at least within half a year'. (D) Teeth brushing behavior: 'do you think that you should brush your teeth after meals?' the answer was classified as 'incorrect' if they did not brush their teeth after meals and use dental floss at least once per day, or 'correct' if they brushed their teeth after meals and used dental floss at least once per day'. (E) Frequency of brushing teeth: 'how many times do you brush your teeth per day?'

Participants' characteristics were obtained through structured questions relating to age (year of birth), gender, marital status, economic status (3 levels were categorized as good, fair/not bad, poor/bad), and educational attainment (receiving educational year or graduated school level).

\section{Statistical analysis}

Analysis was conducted using SPSS 17 statistical software (SPSS INC., Chicago, IL). Coded data were subjected to range and manual checks for accuracy. To compare personal factors or health promoting behavior in various $\mathrm{ABC}$ consumption groups, the Chi-square statistic for testing equality of proportions or rates was used. Final models using binary logistic regression for analyzing betel-nut and cigarette consumption were chosen, based on likely and relevant confounders after univariate analysis (candidate correlates were excluded from the final analyses if $\mathrm{p}>0.05$ in the univariate analysis with outcome variable). Statistical significance was set at $p<0.05$.

\section{Results}

\section{Demographics and health related behavior}

According to the statistics on household registration, the total of adult residents living in the 27 villages was 47,798 [19]. As several worked out of these townships, the baseline questionnaire was sent to 6,911 residents; $708(10.2 \%)$ were not recruited to this study due to being too young, and others were rejected as they were unavailable for interview. Of the remaining 6,203 participants, $83.4 \%$ had lived in the community for $>20$ years and $57 \%$ were female $(3,501)$. The mean age was $49.4 \quad(\mathrm{SD}=16.4$, range 20-95) years, with $78 \%(4,819)$ being in the range from 20 to 64 years. More than half $(3552,58 \%)$ were not educated past middle school. The majority (78\%) was married, $39 \%$ had no occupation, and $25.1 \%$ worked in farming or fishing. Twenty-one percent $(1,268)$ rated their economic status as poor and difficult, while $78 \%$ considered it average.

More than one-third of the participants $(2,153 ; 35 \%)$ reported that they regularly consumed alcohol, 17\% $(1,017)$ chewed betel-nut and $26 \%(1,576)$ smoked cigarettes. Furthermore, 14\% (872) reported regularly consuming betel-nut and cigarettes, and 9\% (522) regularly consumed $\mathrm{ABC}$. The beginning mean (median, range) age of using $\mathrm{ABC}$ was 23 (20,12-71), 24 (21, 13-65), and 21 years of age $(21,10-71)$, respectively. 


\section{$A B C$ consumption is associated with personal factors and health promoting behavior}

There were few differences between the personal factors and health promoting behavior in the alcohol, betel-nut chewing and cigarette smoking groups. Table 1 shows that subjects at study entry who consumed alcohol regularly were predominantly male $(\mathrm{p}<0.001)$, with a high school or college education $(\mathrm{p}<0.001)$, below 64 years of age $(\mathrm{p}<0.001)$, with good or fair economic status $(\mathrm{p}<$ $0.001)$, often adopting physical activity $(\mathrm{p}<0.01)$, not consuming vegetable and fruit $(\mathrm{p}<0.001)$, not attending regular dental check-ups $(\mathrm{p}<0.001)$ and brushed their teeth infrequently $(\mathrm{t}=5.4,95 \% \mathrm{CI}=0.08 \sim 0.17, \mathrm{p}<$ 0.001). The characteristics and factors associated with

Table 1 Demographic characteristics, health promoting behaviors and alcohol, betel-nut and cigarette consumption

\begin{tabular}{|c|c|c|c|}
\hline \multirow[t]{2}{*}{ Variables } & \multicolumn{2}{|r|}{ Consumption N (\%) } & Cigarette \\
\hline & Less $^{1} /$ Regular $^{2}$ & Less $^{1} /$ Regular $^{2}$ & Less $^{1} /$ Regular $^{2}$ \\
\hline Mean, median, range & $23,20,12 \sim 71$ & $24,21,13 \sim 65$ & $21,20,10 \sim 71$ \\
\hline Gender & $x^{2}=906.7^{* * *}$ & $x^{2}=1077.1^{* * *}$ & $x^{2}=1636.4^{* * *}$ \\
\hline Female & $2880(83.7) 560(16.3)$ & 3394 (97.8) 75 (2.2) & $3283(94.8) 180(5.2)$ \\
\hline Male & $1160(46.8) 1319$ (53.2) & $1780(67.3) 866(32.7)$ & $1332(49.8) 1341(50.2)$ \\
\hline Educational level & $x^{2}=267.6^{* * *}$ & $x^{2}=147.7^{* * *}$ & $x^{2}=131.8^{* * *}$ \\
\hline$<=$ middle school & $2542(76.8) 770(23.2)$ & $2849(82.5) 606$ (17.5) & 2652 (76.7) 804 (23.3) \\
\hline$=$ high school & $658(54.2) 557$ (45.8) & $1002(79.4) 260(20.6)$ & $810(63.7) 462$ (36.3) \\
\hline$>=$ college & 807 (59.6) 546 (40.4) & $1288(94.8) 70(5.2)$ & 1124 (82.3) 242 (17.7) \\
\hline Age (years) & $x^{2}=257.5^{* * *}$ & $x^{2}=29.1^{* * *}$ & $x^{2}=57.0^{* * *}$ \\
\hline $20 \sim 39$ & $1229(59.1) 852(40.9)$ & 1826 (86.6) 283 (13.4) & 1541 (72.5) 585(27.5) \\
\hline $40 \sim 64$ & $1683(66.9) 832(33.1)$ & $2167(81.7) 484(18.3)$ & 1945 (73.4) 705 (26.6) \\
\hline $65 \sim$ & $1138(85.1) 200(14.9)$ & $1193(87.0) 178(13.3)$ & 1141 (82.9) 235 (17.1) \\
\hline Economic status $^{3}$ & $x^{2}=20.7^{* * *}$ & $x^{2}=36.9^{* * *}$ & $x^{2}=16.1^{* * *}$ \\
\hline Good & $80(70.8) 33(29.2)$ & 103 (88.8) 13 (11.2) & $93(80.2) 23(19.8)$ \\
\hline Fair/not bad & 3091 (66.8) 1537 (33.2) & $4092(85.9) 673(14.1)$ & 3646 (76.2) 1137 (23.8) \\
\hline Poor/bad & 795 (73.8) $282(26,2)$ & $892(78.8) 240$ (21.2) & $802(70.8) 330(29.2)$ \\
\hline Physical activity ${ }^{4}$ & $x^{2}=8.3^{* *}$ & $x^{2}=15.5^{* * *}$ & $x^{2}=14.1^{* * *}$ \\
\hline Not often & 2138 (69.9) 919 (30.1) & $2630(82.8) 545(17.2)$ & 2332 (73.2) 853 (26.8) \\
\hline Often & 1912 (66.5) 965 (33.5) & 2556 (86.6) 400 (13.5) & 2295 (77.4) $672(22.6)$ \\
\hline Vegetable and fruit & $x^{2}=34.1^{* * *}$ & $x^{2}=25.5^{* * *}$ & $x^{2}=50.6^{* * *}$ \\
\hline Not often & 3506 (67.2) 1709 (32.8) & $4536(84.0) 863(16.0)$ & $4019(74.2) 1400$ (25.8) \\
\hline Often & 447 (79.3) 117 (20.7) & $528(92.0) 46(8.0)$ & $502(87.6) 71(12.4)$ \\
\hline Dental check-up & $x^{2}=27.2^{* * *}$ & $x^{2}=51.6^{* * *}$ & $x^{2}=23.7^{* * *}$ \\
\hline Not regular & 2158 (71.4) 863 (28.6) & $2583(81.8) 574(18.2)$ & 2309 (73.0) 852 (27.0) \\
\hline Regular $^{5}$ & $1584(64.8) 859$ (35.2) & $2203(88.7) 280(11.3)$ & 1963 (78.6) 533 (21.4) \\
\hline Tooth brush & $x^{2}=0.4$ & $x^{2}=38.4^{* * *}$ & $x^{2}=19.3^{* * *}$ \\
\hline Incorrect & 2967 (68.0) 1395 (32.0) & 3754 (82.9) 775 (17.1) & $3356(73.8) 1193(26.2)$ \\
\hline Correct & $1083(68.9) 489$ (31.1) & $1432(89.4) 170$ (10.6) & 1271 (79.3) 332 (20.7) \\
\hline Tooth brush ${ }^{6}$ & $\mathrm{t}$ value $=5.4^{* * *}$ & t value $=7.0^{* * *}$ & t value $=8.2^{* * *}$ \\
\hline (mean, sd) & $1.82(0.7) 1.69(0.6)$ & $1.80(0.7) 1.60(0.7)$ & $1.82(0.7) 1.62(0.6)$ \\
\hline $95 \% \mathrm{Cl}$ & $.08 \sim .17$ & $.15 \sim .27$ & $.16 \sim .26$ \\
\hline
\end{tabular}

${ }^{1}$ Less consumption: The amount of $A B C$ consumption was never or less or quit more than one year.

${ }^{2}$ Regular consumption: The amount of $A B C$ consumption was more than recommended by medical experts.

${ }^{3}$ Self-perceived economic status.

${ }^{4}$ Often: regular physical activity at least 30 minutes per day or 150 minutes a week.

${ }^{5}$ Regular: dental check up/per half year, which coverage by National Health Insurance.

${ }^{6}$ Mean frequency of tooth brush per day and $95 \%$ confidence interval.

${ }^{*} \mathrm{p}<.05{ }^{* *} \mathrm{p}<.01{ }^{* * *} \mathrm{p}<.001$. 
betel-nut chewing or cigarette smoking were comparable (Table 1).

Table 2 shows that betel-nut and cigarette consumption was associated with males $\left(\chi^{2}=1761.2, \mathrm{p}<0.001\right)$ that had received less education $\left(\chi^{2}=169.9, \mathrm{p}<0.001\right)$, aged between 40-64 $\left(\chi^{2}=44.5, \mathrm{p}<0.001\right)$, had poor economic status $\left(\chi^{2}=34.4, \mathrm{p}<0.001\right)$, did not often adopt physical activity $\left(\chi^{2}=20.1, \mathrm{p}<0.001\right)$, did not often consume vegetable and fruit $\left(\chi^{2}=56.3, \mathrm{p}<0.001\right)$, did not regularly have dental check-ups $\left(\chi^{2}=44.4, \mathrm{p}<0.001\right)$ and brushed their teeth infrequently $\left(\chi^{2}=32.9, \mathrm{p}<0.001\right)$. The mean frequency of tooth brushing per day in the betel-nut and cigarette group was significant less than the other 2 groups $(\mathrm{F}=38.6, \mathrm{p}<0.001$, Table 2$)$.

\section{Correlation of betel nut and cigarette consumption}

The logistic regression model (Table 3) indicated that males were 9.8 times more likely have indulge in $\mathrm{BC}$

Table 2 Betel nut and/or cigarette consumption associated with personnel factors and health promoting behaviors

\begin{tabular}{|c|c|c|c|c|}
\hline \multirow[t]{3}{*}{ Variables } & \multicolumn{3}{|c|}{ Number of betel-nut and/or cigarette consumption ${ }^{1}$} & \multirow[t]{3}{*}{$x^{2}$} \\
\hline & \multirow[t]{2}{*}{0} & 1 & \multirow{2}{*}{$\begin{array}{c}2 \\
\text { BC user: } 14 \%\end{array}$} & \\
\hline & & $B^{3}$ user: $17 \% C^{4}$ user: $26 \%$ & & \\
\hline Gender & & & & $1761.2^{* * *}$ \\
\hline Female & $3228(93.4)$ & $206(6.0)$ & $23(0.7)$ & \\
\hline Male & $1214(46.1)$ & $670(25.5)$ & $748(28.4)$ & \\
\hline Educational level & & & & $169.9^{* * *}$ \\
\hline$<=$ middle school & $2517(73.2)$ & $448(13.0)$ & $472(13.7)$ & \\
\hline$=$ high school & $784(62.4)$ & $238(18.9)$ & $235(18.7)$ & \\
\hline$>=$ college & $1113(82.1)$ & $182(13.4)$ & $60(4.4)$ & \\
\hline Age (years) & & & & $44.5^{* * *}$ \\
\hline $20 \sim 39$ & $1513(72.2)$ & $327(15.6)$ & $257(12.3)$ & \\
\hline $40 \sim 64$ & $1854(70.3)$ & $391(14.8)$ & $393(14.9)$ & \\
\hline $65 \sim$ & $1086(79.3)$ & $160(11.7)$ & $124(9.1)$ & \\
\hline Economic status & & & & $34.4^{* * *}$ \\
\hline Good & $89(76.7)$ & $18(15.5)$ & $9(7.8)$ & \\
\hline Not bad & $3522(74.2)$ & $674(14.2)$ & $551(11.6)$ & \\
\hline Difficult/very bad & $759(67.5)$ & $168(14.9)$ & $198(17.6)$ & \\
\hline Physical activity ${ }^{2}$ & & & & $20.1^{* * *}$ \\
\hline Not often & $2242(71.0)$ & $458(14.5)$ & $457(14.5)$ & \\
\hline Often & $2211(75.0)$ & $420(14.2)$ & $317(10.8)$ & \\
\hline Vegetable and fruit & & & & $56.3^{* * *}$ \\
\hline Not often & $3858(71.8)$ & $813(15.1)$ & $706(13.1)$ & \\
\hline Often & $494(86.4)$ & $40(7.0)$ & $38(6.6)$ & \\
\hline Dental check-up & & & & $44.4^{* * *}$ \\
\hline Not regular & $2199(70.0)$ & 479 (15.2) & $463(14.7)$ & \\
\hline Regular & $1911(77.1)$ & $334(13.5)$ & $233(9.4)$ & \\
\hline Tooth brush- & & & & $32.9^{* * *}$ \\
\hline Incorrect & $3209(71.2)$ & $670(14.9)$ & $630(14.0)$ & \\
\hline Correct & $1244(77.9)$ & $208(13.0)$ & $144(9.0)$ & \\
\hline Frequency of tooth brush & & & & $F=38.6^{* * *}$ \\
\hline (mean, SD) & $1.83(0.7)$ & $1.64(0.6)$ & $1.58(0.6)$ & Scheffe \\
\hline $95 \% \mathrm{Cl}$ & $1.80 \sim 1.85$ & $1.58 \sim 1.70$ & $1.53 \sim 1.64$ & $0>1>2$ \\
\hline
\end{tabular}

${ }^{1} 0=$ none habit of betel-nut or cigarette consumption, $1=$ one habit of betel-nut or cigarette, $2=$ both habits of betel-nut and cigarette.

${ }^{2}$ Often: regular physical activity at least 30 minutes per day or 150 minutes a week.

${ }^{3} \mathrm{~B}=$ betel-nut.

${ }^{4} \mathrm{C}=$ cigarette.

${ }^{*} \mathrm{p}<.05{ }^{* *} \mathrm{p}<.01{ }^{* * *} \mathrm{p}<.001$. 
Table 3 The logistic regression of betel-nut and cigarette consumption and associated factors

\begin{tabular}{|c|c|c|c|c|}
\hline Variables & $\beta$ & Odds ratio & $95 \% \mathrm{Cl}$ & $P$ \\
\hline \multicolumn{5}{|l|}{ Gender } \\
\hline Male & 2.28 & 9.77 & $8.08 \sim 11.82$ & $<.001$ \\
\hline \multicolumn{5}{|l|}{ Female* } \\
\hline \multicolumn{5}{|l|}{ Educational level } \\
\hline$<=$ middle school & .50 & 1.65 & $1.25 \sim 2.18$ & $<.001$ \\
\hline$=$ high school & .91 & 2.49 & $1.93 \sim 3.22$ & $<.001$ \\
\hline \multicolumn{5}{|l|}{$>=$ colleg $\mathrm{e}^{*}$} \\
\hline \multicolumn{5}{|l|}{ Age (years) } \\
\hline $20 \sim 39$ & .85 & 2.34 & $1.72 \sim 3.19$ & $<.001$ \\
\hline $40 \sim 64$ & .61 & 1.85 & $1.45 \sim 2.34$ & $<.001$ \\
\hline \multicolumn{5}{|l|}{$65 \sim *$} \\
\hline \multicolumn{5}{|l|}{ Economic status } \\
\hline Poor/bad & .56 & 1.75 & $0.93 \sim 3.29$ & .08 \\
\hline Fair/not bad & .26 & 1.30 & $0.72 \sim 2.34$ & .39 \\
\hline \multicolumn{5}{|l|}{ Good* } \\
\hline \multicolumn{5}{|l|}{ Physical activity } \\
\hline Not often & .22 & 1.25 & $1.04 \sim 1.49$ & .013 \\
\hline \multicolumn{5}{|l|}{ Often* } \\
\hline \multicolumn{5}{|l|}{ Dental check-up } \\
\hline Not regular & .31 & 1.29 & $1.02 \sim 1.63$ & .001 \\
\hline \multicolumn{5}{|l|}{ Regular* } \\
\hline \multicolumn{5}{|l|}{ Tooth brush } \\
\hline Incorrect & .35 & 1.42 & $1.12 \sim 1.80$ & .004 \\
\hline Correct* & & & & \\
\hline
\end{tabular}

Note: * as reference.

consumption than females $(\mathrm{OR}=9.77, \mathrm{p}<0.001)$. Participants with middle and high school education were 1.65 $(\mathrm{p}<0.001)$ and $2.5(\mathrm{p}<0.001)$ times more susceptible to betel-nut and cigarette consumption regularly than those with a college education, respectively. Those aged 40-64 were 1.85 times $(\mathrm{p}<0.01)$ more susceptible to regular betel-nut and cigarette consumption than those aged over 65, although there was a relationship between vegetable and fruit intake and $\mathrm{BC}$ consumption in univariate analysis (Table 2). However, after controlling other confounders, vegetable and fruit intake was not an important correlate in the logistic regression model. Subjects that were less physically active, did not attend regular dental check-ups, and incorrectly brushed their teeth were $1.25,1.29$ and 1.42 times more susceptible to $\mathrm{BC}$ habits than others, respectively.

\section{Discussion}

The findings indicate a high prevalence of $\mathrm{ABC}$ consumption among adult community residents around areas with a high incidence of oral cancer. Regular users of betel quit and cigarettes are associated with low social economic status and adopting a less health promoting lifestyle. $\mathrm{ABC}$ consumption was also significantly associated with males.

\section{High prevalence of $\mathrm{ABC}$ consumption among adult residents around high oral cancer areas}

This study did not use random sampling, but a significantly higher percentage of $\mathrm{ABC}$ consumption, compared with national data, was identified. The prevalence of $\mathrm{ABC}$ consumption was identified in $35 \%, 17 \%$, and $26 \%$ of participants, respectively. In addition, when considering the gender difference, males that regularly consumed $\mathrm{ABC}$ were $53.2 \%, 32.7 \%$ and $50.2 \%$, respectively. These numbers were higher than the nation-wide percentages among both genders. In males aged over 18 years, the prevalence of current $\mathrm{ABC}$ behavior was $18.8,13.0$ and $35.0 \%$, respectively [10]. These differences may be due to location and professions. Most people who live in south-western coastal Yunlin County are farmers and fishermen. Based on the finding of Lee et al. [20], the highest prevalence of betel quid chewing and cigarette smoking in Taiwan is in agriculture or fisheries. This study also found that $14 \%$ regularly consumed both betel quid and cigarettes, and $9 \%$ consumed A, B and $\mathrm{C}$ regularly. This finding is similar to Ko et al. [5], which shows that, despite the Taiwan government conducting several strategies during the last two decades, problems persist.

To compare these habits with other countries, Ghani et al. [8] reported that in Malaysian adults $8.2 \%$ were betel quid chewers, a habit that was more prevalent among females. Females $>40$ years old with Indian ethnicity and a history of smoking were likely to develop a quid chewing habit. Despite betel nut and cigarette consumption, the prevalence of alcohol consumption is similar to Germany and South Korea. Donath et al. [21] found higher alcohol consumption in rural than urban areas in Germany, and Chung et al. [22] found that of the males, $90 \%$ are likely to drink excess alcohol in South Korea.

The age of starting to use $A B C$ was very young - 12 years old for drinking alcohol, 13 for betel nut chewing and 10 for smoking cigarettes. Moreover, many betel nut users become cigarette smokers and alcohol drinkers. In the last 10 years, the Taiwan government incorporated several strategies to reduce the prevalence of $\mathrm{ABC}$ consumption, including legislation to increase the price or tax [7]. However, it is unknown why western coastal adults living around areas with high incidence of oral cancer partake of these 3 unhealthy habits. Do they know the etiology and mechanism(s) of oral cancer associated with $\mathrm{ABC}$ ? Do the health and education policies penetrate into rural areas and the socially economic disadvantaged 
community residents? This may suggest that to understand more fully the complexity of consumption of $\mathrm{ABC}$; investigators need to develop and use sensitive measures that can capture the multidimensional aspects of $\mathrm{ABC}$ behavior in these areas.

Participants who chewed betel-nut and consumed cigarettes tended to be male, less well educated, middleaged, with poor economic status and an unhealthy life style (Table 2). These findings are similar to the results of Shieh et al. [23] who described the prevalence of chewing betel-nut and cigarette smoking in the general population 18 or more years of age in Chiayi city, a south-western coastal city of Taiwan. Based on this finding, the researchers will develop culturally and linguistically competent health education materials for this group in the future.

This study shows an inconsistent finding in the logistic regression model that alcohol users tend to have a better education, higher economic status, adopt more physical activity and receive regular dental check-ups. This phenomenon could be due to the questionnaire not including measuring and quantifying alcohol type, such as the brands of wine they drank, although beer is popular nation-wide with the percentage of alcohol being below 5\%. Small volumes of alcohol may have positive effects on health [15]. The consequence could explain the false higher figure of alcohol consumption in this study. Therefore, we suggest a further study to consider the issue of health literacy and adequate $\mathrm{ABC}$ information, culture-oriented educational material or adapted language-sensitive pamphlets, and that it should take the alcohol type into account for middle aged community residents in regions with a high prevalence of oral cancer.

\section{More specific health promotion programs are necessary initiated in the western coastal rural areas}

Comparing the data with nationwide statistics, participants exercised (56.5 vs. $48 \%$ ) and used dental floss (55.4 vs. $39 \%)$ less often than the general population [7]. Betel nut and cigarette users also used dental floss significantly less (9.0\%) and took less exercise (14.5\%) than those without these 2 habits (Table 2). Oral health and exercise are recognized as important health-related behavior conducive to good mental and physical well-being $[7,13]$. Experts recommend brushing teeth often or at least twice a day, flossing teeth daily and regularly attending dental check-ups every 6 months [13]. Professional oral health resource and access to dental services are limited in rural areas. Therefore, community nurses should conduct health promoting programs related to the low cost, but effectiveness, of oral hygiene and physical activity through community-based health development, specifically for the social economic minority and males in rural areas.
In March 1995, Taiwan's national health insurance (NHI) program was set up with the goal of providing high quality, affordable healthcare to all (NHI covers 99\% of the population) [24]. However, in the last 5 years, financial difficulties and conflicts between government and the public led to the NHI program becoming unstable. Enhancing health promoting programs might reduce the health-related incidence of chronic disease. Furthermore, national statistics showed that life expectancy in Yunlin County is 3 years less in males compared with Taiwan population (73.4 vs. 76.1 years) [24]. It is common for men to die at a younger age than women worldwide [1], but the average is 6 years in Taiwan (76.1 vs. 82.6 years) [24].

Several studies have indicated that it is not only the male gender that is associated with these 3 kinds of behavior $[22,25]$, but that socioeconomic inequalities are important $[10,26,27]$, with poor education, low economic status and living in rural areas being associated with $\mathrm{ABC}$ use $[21,26]$. Our findings indicate that 4.5\% (122) of alcohol, 13.4\% (360) of betel nut, and 13.3\% (357) of cigarette users reported abstinence for $>1$ year. Therefore, it is possible to initiate health promoting programs to reduce the prevalence of $\mathrm{ABC}$ behaviors if the appropriate and cultivated culture-tailed strategies are used. Physical inactivity is a modifiable risk factor for several chronic conditions and a leading cause of premature mortality. An increasing proportion of adults worldwide do not engage in a level of physical activity sufficient to prevent or alleviate these adverse effects [13]. It is time, therefore, that we had nurse-led primary healthcare with an emphasis on health promoting strategies for disadvantaged people living in high behaviour-related cancer areas.

A few limitations must be considered when interpreting our findings. First, the cross-sectional nature of the data poses a limitation and prevents the inference of causal relationships. Second, self-reporting often underestimates true alcohol intake; and because there were more women participants in this study, the prevalence of $A B C$ users might have been an underestimate. Third, several unaccounted factors (i.e., exposure to media messages about tobacco or alcohol or betel-nut, price or cost of $\mathrm{ABC}$, psychiatric disorders, and use of other substances) could have affected the residents' $\mathrm{ABC}$ behavior.

\section{Conclusion}

This is the preliminary outcome of a nursing faculty's longitudinal cohort study that cooperated with a multidisciplinary research team in an area of high prevalence of behavior-related cancer. It has identified that a high percentage of community adults living around the western coastal region regularly consumed $\mathrm{ABC}$. Betel-nut and cigarette users were usually male, middle aged, with a poor 
attitude to health promoting behavior. Betel nut chewers are likely to smoke and drink, and usually do not take part in regular physical activity and have poor oral hygiene. Further research is required to understand the reasons why the subjects consume $\mathrm{ABC}$, and explore ways to prevent initiation and enhance cessation of $\mathrm{ABC}$ habits in this population.

\section{Competing interests}

The authors hereby declare that there were no competing interests.

\section{Authors' contributions}

SEG: Conceptualization of the study, study design, data analysis, discussion and editing of the final draft for publication. TJH: Conceptualization of the study and data collection. JCH: Data collection. MSL: Data collection. RMH: Editing of the final draft for publication. CHC: Data analysis. MYC: Conceptualization of the study, study design, proposal writing, data analysis, discussion and editing of the final draft for publication. All authors read and approved the final manuscript.

\section{Acknowledgments}

The study was supported by a grant from the Taiwan Formosa Plastic Company (FCRPF 690011). We also thank all participants living around the western coastal region in Yunlin County who helped in the success of this study.

\section{Author details}

${ }^{1}$ College of Nursing, Chang Gung University of Science and Technology (CGUST); Director of the Chronic Diseases and Health Promotion Research Center, CGUST, Chang Gung, Taiwan. ${ }^{2}$ Chang Gung Memorial Hospital, Yunlin, Taiwan. ${ }^{3}$ Division of Endocrinology and Metabolism, Department of Internal Medicine, Chang Gung Memorial Hospital, Yunlin, Taiwan. ${ }^{4}$ Division of Cardiology, Department of Internal Medicine, Chang Gung Memorial Hospital, Yunlin, Taiwan. ${ }^{5}$ College of Nursing \& the Chronic Diseases and Health Promotion Research Center, Chang Gung University of Science and Technology, No. 2, Chia-pu Rd. West Sec, Putz City, Chiayi County 61363, R.O. C. Taiwan.

Received: 9 August 2012 Accepted: 12 March 2013

Published: 21 March 2013

\section{References}

1. International Council of Nurses: [http://www.icn.ch/images/stories/ documents/publications/PUBLICATIONS]

2. World Health Organization: [http://www.who.int/topics/chronic_diseases/en/].

3. Australian Institute of Health and Welfare: Risk factors contributing to chronic disease, Cat No. PHE 157. Canberra: AlHW; 2012.

4. Ko YC, Huang YL, Lee CH, Chen MJ, Lin LM, Tsai CC: Betel-nut chewing, cigarette smoking and alcohol consumption related to oral cancer in Taiwan. J Oral Pathol Med 1995, 24:450-3.

5. Ko YC, Chiang TA, Chang SJ, Hsief SF: Prevalence of betel quid chewing habit in Taiwan and related socio-demographic factors. J Oral Pathot Med 1992, 21:261-4.

6. Tsai W, Wu M, Wang G, Lee K, Lee C, Lu Y, Yen H, Chu C, Chen Y, Lin T: Chewing areca nut increases the risk of coronary artery disease in Taiwanese men: a case-control study. BMC Publ Health 2012, 12:162. doi:10.1186/1471-2458-12-162.

7. Bureau of Health Promotion: [http://olap.bhp.doh.gov.tw/Search/ ListHealth1.aspx?menu=1\&mode=12\&year=98].

8. Ghani WM, Razak IA, Yang Y, Talib NA, Ikeda N, Axell T, Gupta PC, Handa Y, Abdullah N, Zain RB: Factors affecting commencement and cessation of betel quid chewing behavior in Malaysian adults. BMC Publ Health 2011, 11:82. doi:10.1186/1471-2458-11-82.

9. Lee KW, Kuo WR, Tsai SM, Wu DC, Wang WM, Fang FM, Chiang FY: Different impact from betel quid, alcohol and cigarette: Risk factors for pharyngeal and laryngeal cancer. Int J Cancer 2005, 117(Suppl 5):831-6. doi:10.1002/ijc.21237.
10. Wen CP, Tsai SP, Cheng TY, Chen CJ, Levy DT, Yang HJ, Eriksen MP: Uncovering the relation between betel quid chewing and cigarette smoking in Taiwan. Tob Control 2005, 14:16-22. doi:10.1136/tc.2004.008003.

11. Yang $Y H$, Lee HY, Tung S, Shieh TY: Epidemiological survey of oral submucous fibrosis and leukoplakia in aborigines of Taiwan. J Oral Patho Med 2001, 30:213-19. doi:10.1034/j.1600-0714.2001.300404.x.

12. Wang SC, Tsai CC, Huang ST, Hong YJ: Betel nut chewing and related factors in adolescent students in Taiwan. Public Health 2003, 117:339-45. doi:10.1016/S0033-3506(03)00082-9.

13. World Health Organization: [http://www.who.int/mediacentre/factsheets/ fs349/en/index.html]

14. Kim J, Kim K, Moon J: Alcohol use behaviors and risk of metabolic syndrome in South Korean middle-aged men. BMC Publ Health 2011, 11:489. doi:10.1186/1471-2458-11-489.

15. Shield KD, Taylor B, Kehoe T, Patra J, Rehm J: Mortality and potential years of life lost attributable to alcohol consumption in Canada in 2005. BMC Publ Health 2012, 12:91. doi:10.1186/1471-2458-12-91.

16. Lee CH, Ko YC, Huang HL, Chao YY, Tsai CC, Shieh TY, Lin LM: The precancer risk of betel quid chewing, tobacco use and alcohol consumption in oral leukoplakia and oral submucous fibrosis in Southern Taiwan. Brit J Cancer 2003, 88(Suppl 3):366-72. doi:10.1038/sj. bjc.6600727.

17. Chapman KR, Mannino DM, Soriano JB, Vermeire PA, Buist AS, Thun MJ, Connell C, Jemal A, Lee TA, Miravitlles M, Aldington S, Beasley R: Epidemiology and costs of chronic obstructive pulmonary disease. Eur Respir J 2006, 27(Suppl 1):188-207. doi:10.1183/09031936.06.00024505.

18. Erhardt L: Cigarettesmoking: An undertreated risk factor for cardiovascular disease. Atherosclerosis 2009, 205(Suppl 1):23-32. doi:10.1016/j.atherosclerosis.2009.01.007.

19. Household registration office: [http://mailiao.household.yunlin.gov.tw/ population/population02.asp?m2=16\&yy=99\&mm=08].

20. Lee CF, Ho PS, Kuo YS, Yang YH: Prevalence of betel quid chewing and cigarette smoking to compare by occupation and profession in Taiwan. The Taiwan J Oral Med Sci 2008, 24:182-204.

21. Donath C, GraSZel E, Baier D, Pfeiffe C, Karagulle D, Bleich S, Hillemacher T: Alcohol consumption and binge drinking in adolescents: Comparison of different migration backgrounds and rural vs. urban residence- a representative study. BMC Publ Health 2011, 11:84. doi:10.1186/14712458-11-84.

22. Chung W, Lim S, Lee S: Why is high-risk drinking more prevalent among men than women? Evidence from South Korea. BMC Publ Health 2012, 12:101. doi:10.1186/1471-2458-12-101.

23. Hsieh CJ: Investigation of areca quid chewing and cigarette smoking prevalence rates and the health conscience of betel quid to health for adults in Chiayi city, Master thesis. Kaohsiung Medical University: Department of Oral Hygiene; 2003.

24. Ministry of the Interior: [http://sowf.moi.gov.tw/stat/week/list.htm]

25. Sebena R, Orosova O, Mikolajczyk RT, van Dijk JP: Selected sociodemographic factors and related differences in patterns of alcohol use among university students in Slovakia. BMC Publ Health 2011, 11:849. doi:10.1186/ 1471-2458-11-849.

26. Leinsalu M, Kaposvari C, Kunst AE: Is income or employment a stronger predictor of smoking than education in economically less developed countries? A cross-sectional study in Hungary. BMC Publ Health 2011 11:97. doi:10.1186/1471-2458-11-97.

27. Martinez P, Roislien J, Naidoo N, Clausen T: Alcohol abstinence and drinking among African women: Data from the World Health Surveys. BMC Publ Health 2011, 11:160. doi:10.1186/1471-2458-11-160.

doi:10.1186/1471-2458-13-257

Cite this article as: Guo et al:: Alcohol, betel-nut and cigarette consumption are negatively associated with health promoting behaviors in Taiwan: A cross-sectional study. BMC Public Health 2013 13:257. 